\title{
Management of transient loss of consciousness in emergency department: what's new from 2018 European Society of Cardiology guidelines?
}

\author{
Michele Brignole \\ Arrhythmologic Centre, Department of Cardiology, Ospedali del Tigullio, Lavagna, Italy
}

\section{Introduction}

The first European Society of Cardiology (ESC) guidelines for the management of syncope were published in 2001, with subsequent versions in 2004 and 2009. The last version has been published in March 2018. ${ }^{1}$ One of the most important aspect characterizing this latter document is the management (diagnosis and risk stratification) of patients referred for transient loss of consciousness (TLOC) in Emergency Department (ED).

In general, $1-1.5 \%$ of referrals to the ED are for syncope; of these, about $50 \%$ are hospitalized. The use of clinical decision rules and standardized protocols has not changed this rate significantly. ${ }^{2}$ Hospitalization costs account for $>75 \%$ of the total costs, and most hospitalizations are unnecessary. ${ }^{3}$ Among the patients who present to the emergency department for syncope, $0.8 \%$ die and an average of $3.6 \%$ have some serious outcome within the next 7-30 days. ${ }^{1}$ Therefore, only a small minority will potentially benefit from urgent hospitalization. Unnecessary admission in low-risk patients can be harmful. ${ }^{4}$ One major challenge in syncope management is reduction of inappropriate admissions and inappropriate use of tests while maintaining the safety of the patient. ${ }^{1,3}$ The document gives strong focus to pathways and organizational issues In particular, the guidelines propose a care pathway for management of the patient with TLOC from their arrival in the ED, and give practical instructions on how to set up outpatient syncope clinics (syncope units) aimed at reducing hospitalization, under- and misdiagnoses, and costs.

Correspondence: Michele Brignole, Arrhythmologic Centre, Department of Cardiology, Ospedali del Tigullio, 16033 Lavagna, Italy. Tel.: +39.0185.329567 - Fax: +39.0185.306506.

E-mail: mbrignole@asl4.liguria.it

Key words: European Society of Cardiology; Guidelines; Loss of consciousness.

Conflict of interest: the author declares no potential conflict of interest.

Funding: none.

Received for publication: 19 April 2018

Accepted for publication: 20 April 2018.

This work is licensed under a Creative Commons Attribution 4.0 License (by-nc 4.0).

CCopyright M. Brignole, 2018

Licensee PAGEPress, Italy

Emergency Care Journal 2018; 14:7509

doi:10.4081/ecj.2018.7509

\section{An ambitious goal: towards zero admissions for diagnosis of syncope}

Zero admission will hardly be reached, nevertheless this term indicates a virtuous objective to be aimed. How to approach this goal? The ESC guidelines recommend to follow these 3 steps: i) Manage patients with syncope secondary to a organic disease according that disease; ii) Organize an syncope Observation Unit in ED and link it via fast track with an hospital Syncope Unit; iii) Select the patients who require admission.

Manage patients with syncope secondary to an organic disease according that disease

Syncope is a symptom, not a disease. Identify the underlying cause of syncope. Normally the presenting complaint of syncope can be established. The primary aim for an ED clinician is then to establish an underlying diagnosis, especially those associated with the potential for rapid clinical deterioration. It is the acute underlying disease that most frequently determines short-term adverse events rather than the syncope itself. ${ }^{5}$ Subsequent management will focus on treating this underlying cause (Figure 1). ${ }^{6}$ Many (40$45 \%$ ) non-cardiovascular and some cardiovascular life-threatening underlying conditions are obvious in the ED. ${ }^{7}$ ESC guidelines lists high risk features that suggest the presence of a serious underlying cause and low risk features that suggest a benign underlying cause. Please see also to the article by Reed published in the current issue of this journal. ${ }^{8}$

\section{Organize a syncope observation unit in emergency department and link it via fast track with a hospital syncope unit}

The implementation of novel care pathways and organizational approaches such as ED observation units and syncope in- and outpatient units (Figure 2) offer safe and effective alternatives to admission in the cases listed in Table 1. A single-centre experience consisting of a short stay in the ED under observation up to 48 hours coupled with fast track to a syncope unit reduced the admission rate to $29 \% .{ }^{9}$ Among patients not admitted, 20\% were discharged after a short observation in the ED, $20 \%$ were fast-tracked to the syncope unit, and $31 \%$ were discharged directly from the ED. ${ }^{9}$

\section{Patients with low-risk features}

These patients do not need further diagnostic tests in the ED as they are likely to have reflex, situational, or orthostatic syncope. They may benefit from reassurance, or counseling.

Patients with high-risk features

These patients should be classified as high risk; they require an intensive diagnostic approach and may need urgent treatment and admission. These patients should be monitored (although it is unclear for how long this should be, most studies suggesting up to 6 hours in the ED and up to 24 hours in hospital) in a setting where resuscitation can be performed in case of deterioration. ${ }^{6}$

Patients that have neither high-nor low-risk features

These patients will require expert syncope opinion, which can 
probably be safely managed in an outpatient setting. ${ }^{10}$ There is no direct evidence that admitting patients to hospital changes their outcome, whilst there is evidence that management in an ED observation unit and/or fast-track to a syncope outpatient unit is beneficial. ${ }^{11,12}$

\section{Select the patients who require admission}

The diagnostic tests, procedures, and interventions that may require admission in patients with high-risk features are listed in Table 1.

In practice, following Table 1, the majority of patients affected by unexplained syncope, who usually are admitted for diagnostic purposes, can safely be managed in ED syncope observation unit and in syncope out-patient unit instead of being hospitalized. In those situations, the stay in ED observation unit and the fast-track to syncope out-patient unit allow to downgrade the risk of the patients from high to intermediate or low, thus allowing to avoid hospitalization. Admission remains necessary only for the few of them who require invasive diagnostic procedures, i.e., electrophysiological study or angiography and for those who need treatment or have had injury secondary to syncope.

Table 1. High-risk syncope patients. Criteria favouring stay in an emergency department observation unit and/or fast-track to syncope unit $v$ s requiring admission to hospital. ARVC, arrhythmogenic right ventricular cardiomyopathy; ECG, electrocardiogram; ED, emergency department; SVT, supraventricular tachycardia.

\begin{tabular}{|c|c|}
\hline $\begin{array}{l}\text { Favour initial management in ED observation unit and/ } \\
\text { or fast-track to syncope unit }\end{array}$ & Favour admission to hospital \\
\hline $\begin{array}{l}\text { High-risk features and: } \\
\text { - Stable, known structural heart disease } \\
\text { - Severe chronic disease } \\
\text { - Syncope during exertion } \\
\text { - Syncope while supine or sitting } \\
\text { - Syncope without prodrome } \\
\text { - Palpitations at the time of syncope } \\
\text { - Inadequate sinus bradycardia or sinoatrial block } \\
\text { - Suspected device malfunction or inappropriate intervention } \\
\text { - Pre-excited QRS complex } \\
\text { - SVT or paroxysmal atrial fibrillation } \\
\text { - ECG suggesting an inheritable arrhythmogenic disorders } \\
\text { - ECG suggesting ARVC }\end{array}$ & $\begin{array}{l}\text { High-risk features and: } \\
\text { - Any potentially severe coexisting disease that requires admission } \\
\text { - njury caused by syncope } \\
\text { - Need of further urgent evaluation and treatment if it cannot be } \\
\text { achieved in another way (i.e. observation unit), } \\
\text { e.g. ECG monitoring, echocardiography, } \\
\text { stress test, electrophysiological study, angiography, device malfunction, etc. } \\
\text { - Need for treatment of syncope }\end{array}$ \\
\hline
\end{tabular}

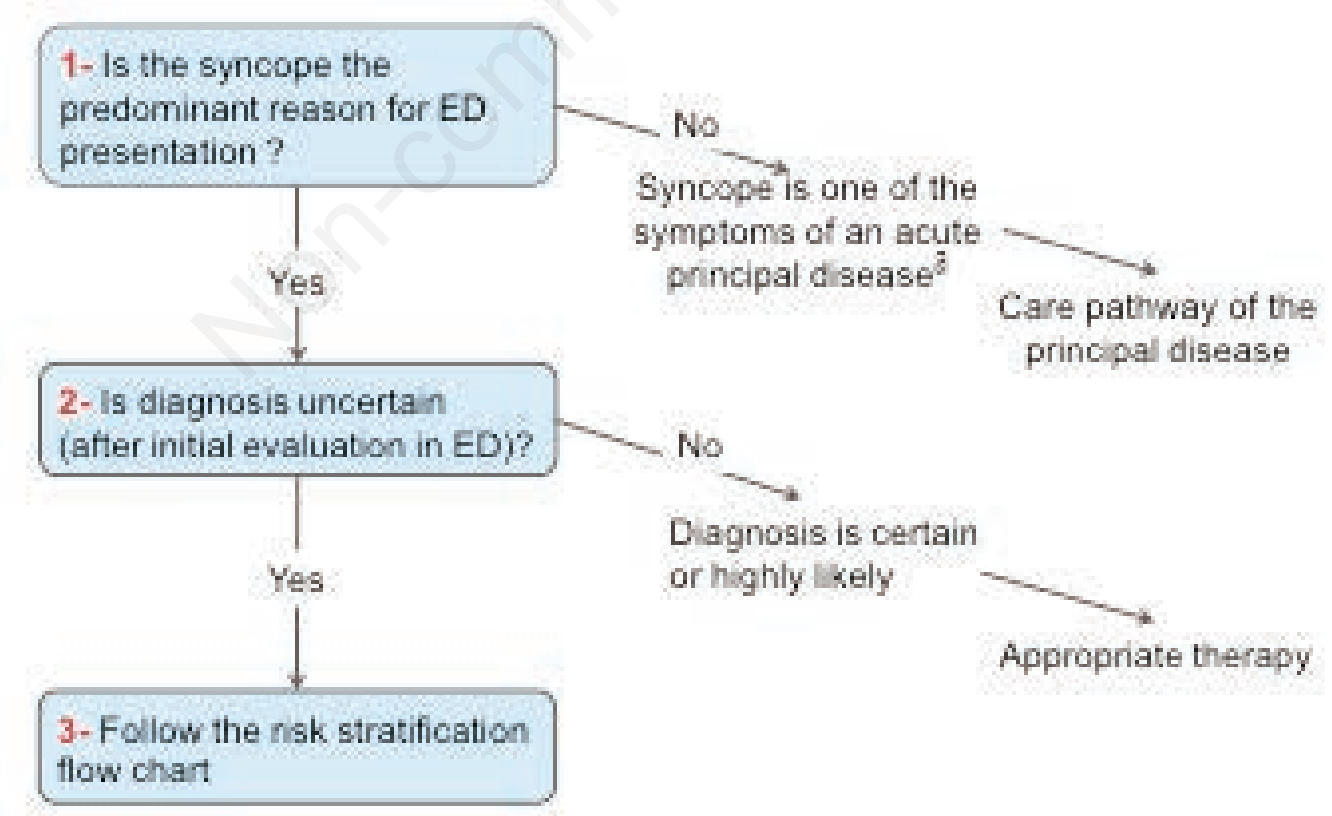

Figure 1. The management of patients presenting to the emergency department (ED) for transient loss of consciousness suspected to be syncope. ${ }^{a}$ This includes pulmonary embolism presenting with shortness of breath, pleuritic chest pain, and syncope, but not trauma secondary to syncope. Reproduced from Brignole M, et al. 2018 ESC Guidelines for the diagnosis and management of syncope. European Heart Journal (2018) 00, 1-69, doi:10.1093/eurheartj/ehy037. Reproduced by permission of Oxford University Press on behalf of the European Society of Cardiology. (c) European Society of Cardiology 2018. All rights reserved. This figure is not included under the Open Access license of this Publication. 


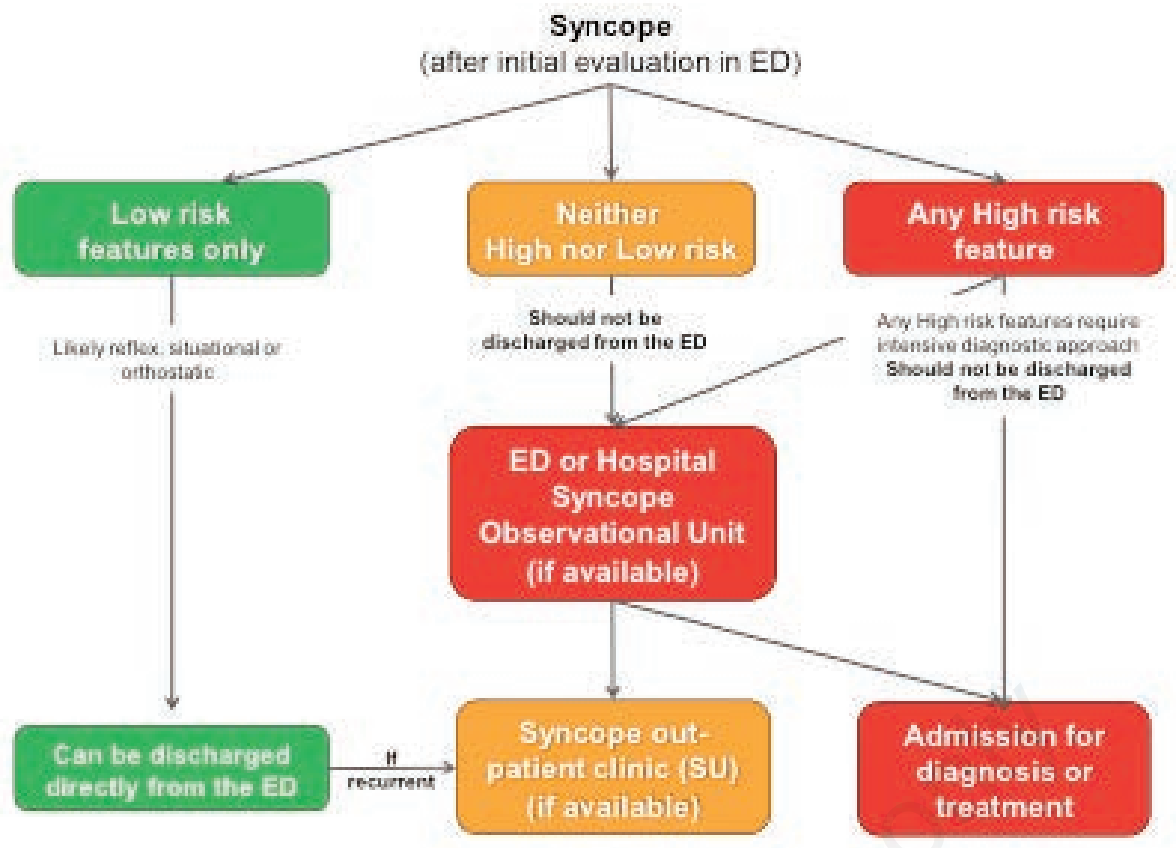

Figure 2. Emergency department (ED) risk stratification flowchart. Reproduced from Brignole M, et al. 2018 ESC Guidelines for the diagnosis and management of syncope. European Heart Journal (2018) 00, 1-69, doi:10.1093/eurheartj/ehy037. Reproduced by permission of Oxford University Press on behalf of the European Society of Cardiology. (c) European Society of Cardiology 2018. All rights reserved. This figure is not included under the Open Access license of this Publication.

\section{References}

1. Brignole M, Moya A, de Lange FJ, et al.; ESC Scientific Document Group. 2018 ESC Guidelines for the diagnosis and management of syncope. Eur Heart J 2018;00:1-69.

2. Serrano LA, Hess EP, Bellolio MF, et al. Accuracy and quality of clinical decision rules for syncope in the emergency department: a systematic review and meta-analysis. Ann Emerg Med 2010;56:362-73.e1.

3. Sheldon RS, Morillo CA, Krahn AD, et al. Standardized approaches to the investigation of syncope: Canadian Cardiovascular Society position paper. Can J Cardiol 2011;27:246-53.

4. Canzoniero JV, Afshar E, Hedian H, et al. Unnecessary hospitalization and related harm for patients with low-risk syncope. JAMA Intern Med 2015;175:1065-7.

5. Numeroso F, Mossini G, Giovanelli M, et al. Short-term prognosis and current management of syncopal patients at intermediate risk: results from the IRiS (Intermediate-Risk Syncope) study. Acad Emerg Med 2016;23:941-8.

6. Casagranda I, Brignole M, Cencetti S, et al. Management of transient loss of consciousness of suspected syncopal cause, after the initial evaluation in the Emergency Department.
Emerg Care J 2016;12:25-7.

7. Reed MJ, Newby DE, Coull AJ, et al. The ROSE (Risk Stratification Of Syncope in the Emergency department) study. J Am Coll Cardiol 2010;55:713-21.

8. Reed M. Management of syncope in the emergency department based on risk stratification. Emerg Care J 2018;14:4-9.

9. Ungar A, Tesi F, Chisciotti VM, et al. Assessment of a structured management pathway for patients referred to the Emergency Department for syncope: results in a tertiary hospital. Europace 2016;18:457-62.

10. Kenny RA, Brignole M, Dan GA, et al. Syncope Unit: rationale and requirement-the European Heart Rhythm Association position statement endorsed by the Heart Rhythm Society. Europace 2015; 17:1325-40.

11. Sun BC, McCreath H, Liang LJ, et al. Randomized clinical trial of an emergency department observation syncope protocol versus routine inpatient admission. Ann Emerg Med 2014;64:167-75

12. Shen WK, Decker WW, Smars PA, et al. Syncope Evaluation in the Emergency Department Study (SEEDS): a multidisciplinary approach to syncope management. Circulation 2004;110:3636-45. 